REVISTA DE ESTUDOS EM ARTES CÊNICAS

E-ISSN 2358.6958

\title{
Ponto de Partida: \\ Um teatro político na ditadura militar
}

Entrevista com Antonio Petrin

Concedida à Marco Antonio Pedra da Silva

Para citar este artigo:

PETRIN, Antonio; SILVA, Marco Antonio Pedra da Silva. Ponto de Partida: Um teatro político na ditadura militar. [Entrevista concedida a Marco Antonio Pedra da Silva]. Urdimento - Revista de Estudos em Artes Cênicas, Florianópolis, v. 3, n. 42, p.1-15, dez. 2021.

doi DOI: http:/dx.doi.org/10.5965/1414573103422021e0501 


\title{
Ponto de Partida: Um teatro político na ditadura militar ${ }^{1}$
}

Entrevista com Antonio Petrin concedida à Marco Antonio Pedra da Silva²

\begin{abstract}
Resumo
Nesta entrevista, o ator Antonio Petrin (1938) comenta a sua participação no elenco da primeira encenação da peça Ponto de Partida (1976), importante musical brasileiro, escrito por Gianfrancesco Guarnieri (1934-2006) e dirigido por Fernando Peixoto (19372012). Trata-se de uma peça de teatro que buscou fazer alusão à morte do jornalista Vladimir Herzog (1937-1975), torturado e assassinado pelo Estado durante a ditadura militar no Brasil (1964-1985). Em maio de 2021, diante da crise sanitária ocasionada pelo novo coronavírus (COVID-19), a entrevista foi realizada através de uma chamada de vídeo.
\end{abstract}

Palavras-chave: Teatro brasileiro. Ditadura Militar. Vladimir Herzog. Antonio Petrin.

\section{Ponto de Partida: A political theater in the military dictatorship}

\begin{abstract}
In this interview, the actor Antonio Petrin (1938) comments his participation in the cast of the first staging of the play Ponto de Partida (1976), an important Brazilian musical, written by Gianfrancesco Guarnieri (1934-2006) and directed by Fernando Peixoto (19372012). It is a play that sought to allude to the death of journalist Vladimir Herzog (19371975), tortured and murdered by the State during the military dictatorship in Brazil (19641985). In May 2021, given the health crisis caused by the new coronavirus (COVID-19), the interview was conducted through a video call.
\end{abstract}

Keywords: Brazilian theater. Military dictatorship. Vladimir Herzog. Antonio Petrin.

\section{Ponto de Partida: Un teatro político en la dictadura militar}

\section{Resumen}

En esta entrevista, el actor Antonio Petrin (1938) comenta su participación en el elenco de la primera puesta en escena de la obra Ponto de Partida (1976), importante musical brasileño, escrito por Gianfrancesco Guarnieri (1934-2006) y dirigido por Fernando Peixoto (1937-2012). Es una obra que buscaba aludir a la muerte del periodista Vladimir Herzog (1937-1975), torturado y asesinado por el Estado durante la dictadura militar en Brasil (1964-1985). En mayo de 2021, ante la crisis de salud provocada por el nuevo coronavirus (COVID-19), la entrevista se realizó a través de una video llamada.

Palabras clave: Teatro brasileño. Dictadura militar. Vladimir Herzog. Antonio Petrin.

${ }^{1}$ Essa entrevista foi realizada no dia 03 de maio de 2021, através da plataforma Google Meets, para o projeto de Iniciação Científica "A encenação de Ponto de Partida em 1976: um estudo dos elementos épicos brechtianos”, financiado pela Fapesp, processo no 2020/08383-0.

${ }^{2}$ Graduando em Artes Cênicas pela Universidade Estadual de Campinas (UNICAMP). Bolsista no Programa de Iniciação Científica da Fundação de Amparo à Pesquisa do Estado de São Paulo (FAPESP), processo 2020/08383-0. marcoantonio.pedrasilva@gmail.com

(7) http://lattes.cnpq.br/2345023723065044 (iD) https://orcid.org/0000-0002-8939-2658 


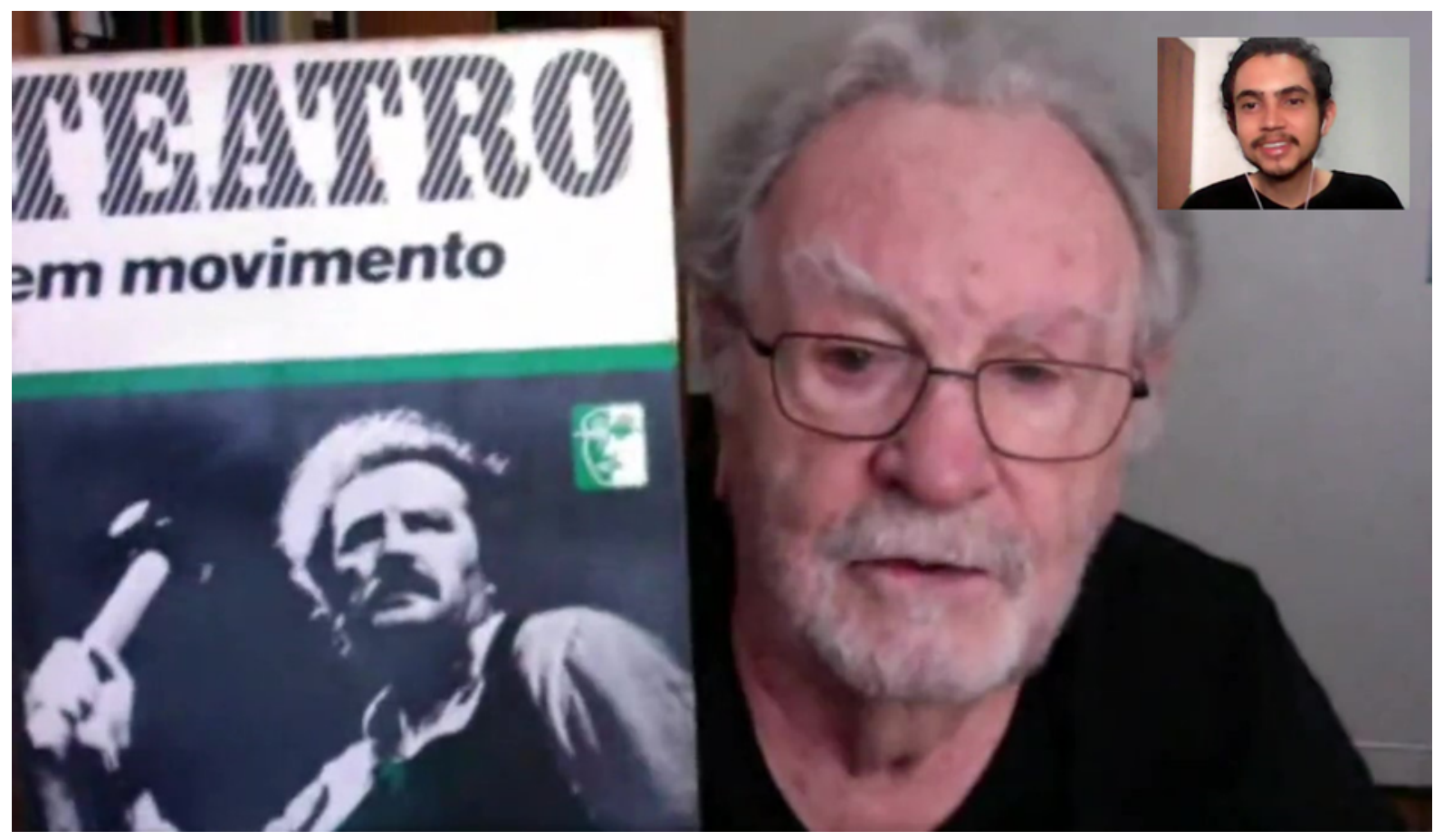

Antonio Petrin é um ator brasileiro formado pela Escola de Arte Dramática em 1967. Ele participou de importantes espetáculos políticos do teatro moderno nacional, como a primeira encenação das peças: Rasga Coração (1979-1981), escrita por Oduvaldo Vianna Filho (1936-1974) e dirigida por José Renato (1926-2011); Ponto de Partida (1976-1977), de Gianfrancesco Guarnieri (1934-2006) com direção de Fernando Peixoto (1937-2012); e Patética (1980), com texto de João Ribeiro Chaves Netto e direção de Celso Nunes (1941).

Essas duas últimas montagens contavam histórias que remetiam à morte do jornalista Vladimir Herzog (1937-1975), assassinado pelo Estado durante a ditadura militar no Brasil (1964-1985). Na época, Herzog era diretor de jornalismo da TV Cultura. Depois de matarem Herzog, os militares penduraram o corpo do jornalista em uma grade, simulando uma cena de suicídio por enforcamento (Kleinas, 2012). Tanto em Patética quanto em Ponto de Partida, Petrin interpretou o personagem que representava o pai de Herzog. 
Nesta entrevista, o ator fala, principalmente, sobre a sua participação no elenco de Ponto de Partida, o alcance de público que essa peça conseguiu obter e as dificuldades que ela enfrentou por causa dos militares.

\section{Você chegou a conhecer o jornalista Vladimir Herzog em vida?}

Eu nunca tive contato com o Herzog, nunca conversei com ele. Mas sabia da presença dele na TV Cultura, principalmente por eu ser colega do Fernando Pacheco Jordão. Quando eu comecei a minha carreira, eu trabalhava na TV Cultura e era muito ligado ao Jordão. Ele era colega do Herzog na redação da TV Cultura, eram da mesma equipe.

\section{Antes da peça Ponto de Partida, o senhor já havia trabalhado com os artistas envolvidos na montagem?}

Já havia trabalhado com o Othon Bastos e com o Fernando Peixoto, que era o diretor do espetáculo. Quando a peça estreou no TAIB (Teatro de Arte Israelita Brasileiro), estavam no elenco o Othon Bastos, a Martha Overbeck, o Gianfrancesco Guarnieri, a Sonia Loureiro e o Sérgio Ricardo, que também é o autor das músicas da peça. Mas o Sérgio Ricardo ficou na peça por muito pouco tempo, apenas vinte dias, e depois precisou sair, não sei qual foi o motivo. E aí o Fernando Peixoto me chamou para entrar no lugar do Sérgio Ricardo. Ou seja, eu não estreei a peça, cheguei vinte dias depois da estreia. E, depois que cheguei, o Sérgio Ricardo ficou mais alguns dias na peça porque ele dirigia o Grupo Maria Déia, que fazia a parte musical do espetáculo.

Entrei na peça e depois acabei virando capa do livro do Fernando Peixoto [Petrin mostra o livro Teatro em Movimento (1985), de Fernando Peixoto, que tem, na capa, uma foto sua interpretando o Ferreiro, seu personagem em Ponto de Partida].

Em São Paulo, fizemos uma carreira brilhante no TAIB, ficamos uns oito meses em cartaz nesse teatro. Depois fomos para o Rio de Janeiro, no Teatro João 
Caetano, e ficamos em cartaz por vinte dias. Na praça em frente ao Teatro João Caetano, havia um mar de gente querendo assistir à peça, mas por questões de acordo com o aluguel do Teatro, ficamos apenas vinte dias no João Caetano.

A peça marcou muito o público, porque era uma metáfora sobre a morte do Vladimir Herzog. E o Guarnieri era o poeta do espetáculo, o ator principal. Era fantástica a atuação do Guarnieri fazendo o Dôdo. O personagem do Othon era cego e representava o poder que tinha sido o autor da morte do poeta que apareceu pendurado em uma árvore no centro da praça. Me lembro da primeira fala do Guarnieri: “Mestre Birdo! Desça daí!”. Era realmente forte. As músicas do Grupo Maria Déia também eram fantásticas, traziam elementos do nordeste. Antes de Ponto de Partida, eu nunca havia participado de um espetáculo que eu precisasse cantar. Foi uma experiência gratificante, uma experiência de teatro político. Guarnieri sempre foi um ator preocupado com assuntos políticos. Essa peça veio depois de Um Grito Parado no $A r^{4}$. E o Guarnieri já tinha dado uma mudada no panorama teatral brasileiro com a peça Eles não usam black-ties. Antes de Eles não usam black-tie, o teatro vivia do repertório clássico do TBC (Teatro Brasileiro de Comédia), que era muito bem feito, com vários diretores estrangeiros, italianos principalmente. E o Guarnieri, junto com o José Renato, no Eles Não Usam Black-Tie, fizeram uma ruptura do teatro que se fazia naquele momento. O Guarnieri colocou o operário no palco com Eles Não Usam Black-Tie, uma peça que também foi extraordinária e virou um clássico do teatro brasileiro. Depois vieram outros sucessos, como Um Grito Parado no Ar e Ponto de Partida. Além de tudo, Guarnieri também era um grande ator.

\section{Quanto tempo você teve para substituir o Sérgio Ricardo?}

Eu tive duas semanas. Mas aí eu passei a assistir ao espetáculo todos os dias,

4 Peça de teatro escrita por Gianfrancesco Guarnieri em 1972 e encenada por Fernando Peixoto no ano seguinte. O enredo do texto trata de uma crise financeira enfrentada por uma companhia de teatro que estreará uma peça em dez dias. A fábula de Um Grito Parado no Ar busca fazer uma analogia com o sucateamento cultural promovido pela ditadura militar.

${ }^{5}$ Peça de teatro de Gianfrancesco Guarnieri, encenada em 1958 pela companhia Teatro de Arena de São Paulo, sob direção de José Renato. A montagem foi um grande sucesso de bilheteria, entrou para a história do teatro brasileiro, e salvou o Arena de uma dura crise financeira que o grupo enfrentava na época. 
ia decorando o texto, as marcações... Fiz apenas um ensaio com o grupo todo, que aconteceu no próprio TAIB. Depois disso, entrei no espetáculo. Mais tarde, a Sonia Loureiro sofreu um acidente. Ela se queimou andando de moto. Aí ela teve que ser substituída no espetáculo pela Ana Braga. Eu interpretava o pai do poeta que havia sido assassinado. Quem tinha mais texto era o Guarnieri, o Othon e a Marta, mas de qualquer maneira era o conjunto que fazia essa peça vibrar. E a plateia se emocionava muito com a peça, com o texto... E também deve-se salientar a cenografia do Gianni Ratto, que coloca um boneco pendurado em uma árvore e um praticável, que se abria e era de onde entrava o Othon e a Martha para fazerem suas cenas. Era um grande arranjo.

\section{O Grupo Maria Déia estava presente em todos os ensaios?}

Não. Essa parte da música tinha um momento de ensaio só com eles. Era muito pouca a minha participação nessa parte, eu cantava junto com a Sonia Loureiro. Não tinha muita música para eu cantar. E o Grupo Maria Déia fazia um contraponto no espetáculo, mas eles não cantavam no espetáculo. Eles introduziam momentos musicais. A única música que eu cantava com a Sonia falava do desaparecimento do filho do ferreiro e da dor que ele estava sentindo. Eu me lembro que ficamos muito amigos dos músicos do Maria Déia.

\section{Em quais cidades vocês apresentaram a peça?}

A gente apresentou em São Paulo, Campinas, Santo André e no Rio de Janeiro. Depois, fui trabalhar com o Othon Bastos em uma outra peça chamada Mortos Sem Sepultura. Foi uma época de um teatro político forte, sempre driblando a ditadura militar.

Em São Paulo, além de nos apresentarmos no TAlB, também nos apresentamos no Teatro Municipal. Na época, havia um projeto da Secretaria de Cultura de São Paulo que reservava uma semana para que os melhores espetáculos em cartaz se apresentassem no Teatro Municipal a preços bem 
populares. E eu me lembro que, na primeira noite que apresentamos Ponto de Partida no Teatro Municipal, houve uma agitação muito grande de pessoas em passeatas protestando contra a ditadura. Me lembro de ter participado de algumas dessas passeatas. E, nesse dia, após participar de uma delas, me dirigi ao Teatro Municipal e o prédio estava totalmente cercado pela cavalaria dos militares. E os cavalos dos militares cagaram em frente à praça Ramos de Azevedo. Era uma coisa horrível. Eu pensei: “Ixi, hoje não vem ninguém no teatro". Para a nossa surpresa, o teatro lotou. O Teatro Municipal deve ter cerca de mil e duzentos lugares e naquela noite ficou absolutamente lotado.

O Guarnieri e o Othon prepararam um manifesto que eles pretendiam ler para a plateia contra aquela situação que estava acontecendo. Mas a leitura desse manifesto foi proibida pela direção do Teatro Municipal. Era uma época difícil, porque tudo era proibido. Mas a semana no teatro municipal foi um sucesso de público, lotava todos os dias.

\section{Como era ter o Guarnieri no elenco? Ter o dramaturgo com vocês, ajudava na encenação?}

Ele não interferia em nada. Ele representava. Comigo, principalmente, como eu entrei depois, ele dava um ou outro toque. Eu contracenava muito com ele. Mas ele não interferia no espetáculo propriamente dito. Ele era um colega fantástico, convivemos muito bem. Devo dizer que eu ficava embevecido ao lado dele em cena, vendo ele representar. Ele tinha um monólogo que eu ficava ao lado dele ouvindo. Era uma coisa muito preciosa ver esse cara interpretar com tanta magia, com tanta emoção, aquele texto que ele escreveu. Eu era um privilegiado por estar no palco ao lado dele, olhando no olho. Até me arrepia lembrar. Esse texto que ele dizia é uma poesia. Aliás, a escrita do Guarnieri tem uma qualidade fantástica. Os textos dele são todos tomados por emoções, com uma atitude política, voltada para o ser humano. Ele nunca escreveu uma peça que não tivesse essa preocupação.

De tanto que eu admirava o Guarnieri, no meu exame de admissão para ingressar na Escola de Arte Dramática, eu fiz uma cena do texto Eles Não Usam 
Black-Tie. Eu escolhi esse texto porque eu já o tinha assistido no teatro amador.

Depois que eu deixei a Escola de Arte Dramática, eu fui convidado pela Fundação das Artes de São Caetano do Sul para fazer um espetáculo. E a proposta foi que eu, juntamente à Fundação das Artes, trouxesse as pessoas da comunidade para formar o elenco. Não eram estudantes da Fundação. Nós abrimos um teste para várias pessoas da comunidade. E aí nós formamos um elenco e eu montei Eles Não Usam Black-Tie. Essa peça gira em torno do filho do Otávio que diante de uma greve decide furá-la.

Quando começamos o trabalho, eu coloquei o personagem do filho do Otávio em julgamento. Perguntei se ele deveria furar a greve ou não. O Guarnieri colocava vários motivos para ele furar a greve: o medo de perder o emprego, um namoro, a espera de um filho... E para a minha surpresa, o elenco absolveu o fura greve, por causa das condições que eu citei, questões bem burguesas. Ensaiamos a peça durante uns três meses, e, quando a gente foi estrear a peça, o Lula, em São Bernardo do Campo, furou a ditadura militar e conseguiu fazer um discurso. E o grupo que fazia a peça acompanhou todo esse processo. Eu os obrigava a acompanhar. Bom, na semana anterior à estreia, eu coloquei novamente o personagem em julgamento. E aí eles condenaram o Tião.

É isso que é interessante nessas peças. Há o conflito de questões políticas. À medida que o povo entende o que está acontecendo, vão ficando mais politizados.

Hoje em dia, a gente vê a falta que faz essa politização. E é por isso que vemos tantos idiotas falando bobagens por aí. Isso acontece porque as pessoas não leem, não ouvem, não entendem e não querem entender. Mas esse meu teste com a peça Eles Não Usam Black-Tie mostrou que, ao entenderem a peça, os atores condenaram o Tião.

A morte de Guarnieri foi lamentável. E eu convivi muito com ele, com Paulo Pontes, Oduvaldo Vianna Filho... Eu fui privilegiado por conviver com tantos dramaturgos importantes. E convivi também muito com Fernando Peixoto, um diretor fantástico. O desaparecimento dessas pessoas tornou a nossa arte muito pobre. Deixamos de fazer teatro. Eu me lembro que, em uma determinada época, 
as pessoas de teatro falavam: "Eu não aguento mais fazer teatro político. É sempre a mesma bobagem." Aí a dramaturgia enveredou para uma dramaturgia superficial, que existe até hoje. Uma dramaturgia que não fala a alma do nosso povo.

Guarnieri foi embora cedo, Paulo Pontes foi embora cedo, Vianinha mais ainda. Vianinha escreveu, na minha opinião, a obra prima da dramaturgia brasileira, Rasga Coração.

Outros artistas desapareceram e a gente espera que surjam novas pessoas para substituir esses caras, mas eu tenho a impressão que vai ser difícil. A gente acaba falando de Ponto de Partida e de toda uma dramaturgia de uma época, quando o teatro estava muito vivo...

Eu me lembro que o Flávio Império dirigiu, com um grupo de estudantes da cidade de São Paulo, uma peça do Bertolt Brecht chamada Os Fuzis da Senhora Carrar. Foi um momento do teatro que era algo delirante ver aquela encenação de estudantes fazendo aquele tipo de espetáculo. Eu me lembro que paralelamente a essa encenação, eu, em Santo André, também dirigi Os Fuzis da Senhora Carrar com uma outra atriz, também formada pela Escola de Arte Dramática, a Dilma. A gente trocava ideias, fazíamos um trabalho em conjunto. O teatro era um estudo enorme. Todos estudavam o teatro. Hoje, dependemos de vocês para fazer com que o teatro tenha vida.

Eu até acabei escrevendo uma peça agora. Me atrevi a escrever uma peça, nunca havia feito isso. A peça é sobre um ator com Alzheimer, e sobre o quanto essa doença interfere na vida de um ator. É baseado numa publicação de Facebook de uma filha de um homem com essa doença. Eu peguei essa ideia e coloquei na boca de um ator que gostava de representar Shakespeare e Plínio Marcos. A peça chama-se O Inútil.

\section{Você já publicou essa peça?}

Ainda não me atrevi a publicar, só mandei para alguns amigos, para ver o que eles acham. Posso mandar para você depois... 


\section{Ficarei muito feliz! Petrin, como o público reagiu ao ver Ponto de Partida?}

O Guarnieri, toda vez que terminava o monólogo dele, era aplaudido. A plateia aplaudia e no final, para sairmos de cena era difícil, porque os aplausos eram muitos. A gente ficava impressionado com a reação da plateia. Naquela época, estava viva a lembrança do Herzog, então essa ligação com a figura do Birdo era muito forte. O caso Herzog foi um momento em que a gente sofreu muito com a ditadura. O Ato Ecumênico na praça da Sé foi um movimento fantástico, grande, um movimento feito por diversas religiões. ${ }^{6}$

Em Ponto de Partida, o público sabia o que havia acontecido e a metáfora da peça só serviu para enganar a censura, mas o público sabia do que estávamos falando.

Depois veio o espetáculo Patética (1980), outra peça sobre o Herzog. Só que Patética não tinha metáfora, contava a vida do Herzog exatamente como foi. Eu fazia o pai do Herzog, a Lilian Lemmertz fazia a mãe, Ewerton de Castro fazia o Herzog. A peça foi escrita pelo cunhado do Herzog, João Ribeiro Chaves Netto.

Para fazer essa peça, eu me lembro que precisei, inclusive, aprender a fazer uma oração judaica que os homens da família fazem durante os sete dias que seguem da morte de outro ente.

Patética não fez sucesso em São Paulo, o público ficou com medo. A peça causava uma grande emoção nas pessoas. Depois, essa peça viajou, eu não pude viajar, mas a peça viajou e fez um baita sucesso. O Celso Nunes, que dirigiu a peça, perdeu dinheiro aqui em São Paulo e depois ganhou dinheiro lá fora.

Gostaria que você falasse sobre o fato de ter interpretado o pai do personagem análogo ao Herzog tanto em Ponto de Partida

\footnotetext{
${ }^{6}$ No dia 31 de outubro de 1975, aconteceu o Ato Ecumênico na Catedral da Sé na cidade de São Paulo em homenagem ao jornalista Vladimir Herzog. "Para celebrá-lo se fizeram presentes o Cardeal D. Paulo Evaristo Arns, pelos católicos, o reverendo Jaime Wright, em nome das Igrejas Evangélicas e, como representante judeu, o rabino Henry Sobel” (Freitas, 2005., p. 31). Para impedir a adesão da população a tal ato, o governo instaurou a "Operação Gutemberg". Nessa operação a força militar "montou barreiras em vários bairros da cidade, dificultando o acesso ao centro" (Freitas, 2005, p. 31) e mandou soldados demasiadamente armados para ficarem próximos da Catedral (Freitas, 2005, p. 31).Apesar disso, oito mil pessoas foram para o ato.
} 


\section{quanto em Patética.}

Um era o pai do poeta morto na praça e o outro do pai que chega ao Brasil. Inclusive, a primeira cena de Patética era dele no navio chegando ao país. Agora, a peça não tinha a mesma qualidade de Ponto de Partida. Apesar de ter sido escrita pelo cunhado do Herzog, ela não tinha a mesma qualidade poética. A plateia sofria muito. Houve, na plateia, um homem que trabalhava de diretor na TV Cultura, ele conviveu com Herzog e foi assistir à Patética. Ele começou a chorar tanto, mas tanto, que começou a atrapalhar a audiência e os atores no palco, tanto que paramos o espetáculo. Além disso, nós achávamos que, aqui em São Paulo, todos os judeus da cidade iriam assistir à peça, mas todos eles se recusaram, não quiseram participar.

\section{Eu imagino que a família Herzog tenha assistido à Patética, estou certo? E Ponto de Partida? Eles assistiram também?}

Patética eles assistiram. A Clarice assistiu, o João Chaves Netto também. Quem fazia o papel da Clarice era a Regina Braga. Ponto de Partida eu não sei se eles assistiram.

\section{Para você, qual foi a importância de estar no elenco de Ponto de Partida?}

É a soma dos trabalhos de um ator que forma uma carreira e uma cabeça. Eu tive o privilégio de participar de uma época em que o teatro era fundamental. A gente costumava dizer assim: universitário que não vai assistir determinadas peças, não vai ter assunto na sua roda de amigos. Se não assistir determinados espetáculos vai ficar só ouvindo, não vai falar nada. Porque o teatro tinha uma importância fundamental na vida universitária e na vida do povo. É claro que também convivemos com os teatrinhos de diversão, as comediazinhas. Isso sempre vai acontecer.

Eu sou do partido que o teatro deve primeiramente ser uma boa diversão, o 
sujeito tem que sair de casa e tem que se divertir e, nessa diversão, algo tem que ficar aqui dentro. Depois do espetáculo, o assunto na pizzaria não deve ser só sobre o sabor da pizza, mas sim, sobre o sabor daquilo que as pessoas assistiram. O teatro tem que fazer com que alguma coisa toque, e isso não pode ser uma teoria, tem que ser prático. E eu posso dizer que eu convivi com essas pessoas que fizeram do teatro brasileiro uma coisa forte. Conviver com Antunes Filho, Fernando Peixoto, Flávio Rangel, Oduvaldo Vianna Filho, Paulo Pontes, Gianfrancesco Guarnieri, Gianni Ratto, com o pessoal do Oficina, eu nunca trabalhei com o Oficina, mas convivia, Renato Borghi, Zé Celso... Participei dos melhores espetáculos que o teatro brasileiro fez.

Eu fazia uma brincadeira, dizia assim: "Eu não posso ver os melhores espetáculos, porque eu estou neles". Olha a minha pretensão! Mas eu dizia isso.

Eu não tinha nada a ver com Ponto de Partida quando a peça estreou, eu fui substituir o Sérgio Ricardo, mas, por alguma razão, Ponto de Partida caiu no meu colo. Pela minha amizade com Fernando Peixoto, pela minha amizade com Othon Bastos. Todos nós formávamos uma pequena máfia de pessoas preocupadas com as mensagens que dizíamos com o teatro.

Eu fiz vários espetáculos com o Flávio Rangel, fiz um espetáculo da Broadway com o Rangel chamado Homem de La Mancha, que falava do Cervantes. Só que o Flávio Rangel, que dirigia essa peça, que era produzida pelo Paulo Pontes, fez desse espetáculo um momento político. Ele transformou o Cervantes em um poeta que estava encarcerado. Conviver com essa gente, fez com que a minha carreira fosse sempre maravilhosa e Ponto de Partida foi um desses momentos normais para mim. Eu entrei no espetáculo, era tudo maravilhoso e eu fiquei deslumbrado, como sempre fico com o teatro de qualidade, com o teatro que fale alguma coisa para o ser humano, que não seja só uma brincadeirinha.

Eu acho que vocês jovens terão essa missão de revitalizar o teatro. Todo mundo fala que o teatro já morreu, mas não morreu nada, desde o quinto século antes de Cristo fala-se que ele vai morrer e ele sempre renasce. O teatro espera que alguém o faça renascer. É claro que ao longo do percurso a gente comete muitos erros, faz muitas barbaridades, faz coisas sem qualidade, é normal. 0 
teatro não precisa de dinheiro, o teatro precisa de duas tábuas e um lampião aceso e já tá bom para fazer qualquer tipo de espetáculo.

O Shakespeare fazia isso. Quando eu fui à Inglaterra ver onde o Shakespeare fazia seus espetáculos, eu pensei: "mas como ele fazia aquelas peças nesse palco?". E ele fazia. Não precisava de muita coisa. Então, fazer Ponto de Partida foi um privilégio, valeu a pena.

Petrin, alguns alunos da Unicamp estão preparando uma leitura dramática da peça Ponto de Partida. Que dica você daria para a pessoa que vai interpretar o papel do Ferreiro?

Agora você me pegou! Nenhum ator imita o outro. Nenhum ator vai fazer igual ao outro. O importante é entender o personagem. Estudar e compreender como esse pai fica ao encontrar o filho pendurado em uma árvore. Essa marreta que ele usa [mostra a capa do livro Teatro em Movimento] tem que servir não só para bater o ferro, mas tem que bater para se revoltar. É a revolta de ver seu filho morto. Qualquer filho que você perde é um trauma, é uma dor. Perder um filho poeta, enforcado pelo poder, traz uma dor muito maior. Então o barulho da batida na bigorna tem que ressoar no espaço. Não falo para ele falar alto, não falo para ele falar baixo, não falo para ele falar depressa, não falo para ele falar devagar... Ele tem que encontrar essa maneira de dizer. Tem que ficar imbuído desse sentimento. Quando tem o sentimento correto, o ator interpreta maravilhosamente bem.

Toda vez que eu pegava um personagem, eu pensava assim: "Se o John Herbert fosse fazer esse papel, como é que ele faria?" "Se o Juca de Oliveira fizesse esse outro personagem, como é que ele faria?”. Então eu ficava imaginando outros atores fazendo e, no fim, eu via que o que eu fazia não tinha nada a ver com o John Herbert ou o Juca de Oliveira, tinha a ver comigo, com o meu entendimento do personagem. Você só pode fazer um personagem quando você entende ele. Quando você entende tudo o que falam dele e tudo o que ele fala para os outros. Essa é a magia do teatro. O teatro não é uma coisa simplesinha, tem que se tornar simples, mas antes tem que haver o entendimento. 
O ator tem que ter dúvida, ele não vai dar conta de fazer seu personagem se tiver muita certeza, porque cada dia ele vai conquistar um pouquinho mais do seu personagem. Os personagens a cada dia têm uma descoberta nova. A cada dia ele descobre um tom diferente. Uma vez eu perguntei para o Fernando Peixoto: "Fernando, depois de você fazer um espetáculo, criar um personagem, colocar em cena, existe alguma possibilidade de mudar?”. Ele respondeu que não. Quando você coloca o personagem em cena, você só vai conseguir mudá-lo em cena, não antes. Se fez errado, fez errado. Não tem como voltar atrás, tem que procurar durante. Enquanto ele está ali representando, ele está entendendo o público, qual é o sentimento do público. Então essa leitura não tem receita. Nem para quem vai fazer o Dôdo, nem o Ferreiro, nem a Maíra, nem os personagens do poder.

\section{Referências}

CHAVES NETTO, João. Patética. Rio de Janeiro: Civilização Brasileira, 1978.

FREITAS, Ludmila Sá de. (1976) História e Dramaturgia: o caso Vladimir Herzog (re)significado por Gianfrancesco Guarnieri em "Ponto de Partida". Trabalho de Conclusão de Curso (Bacharelado de História) - Universidade Federal de Uberlândia, Uberlândia, 2005.

GUARNIERI, Gianfrancesco. O melhor teatro: Gianfrancesco Guarnieri. seleção: Décio de Almeida Prado. 2. ed. - São Paulo: Global, 2001.

KLEINAS, Alberto. A morte de Vladimir Herzog e a luta contra a ditadura: a desconstrução do suicídio. Dissertação (Mestrado em Ciências Humanas) Universidade Federal de São Carlos, São Carlos, 2012.

PEIXOTO, Fernando. Teatro em Movimento. São Paulo: Hucitec, 1985.

VIANNA FILHO, Oduvaldo. Rasga Coração. São Paulo: Temporal, 2018. 
Ponto de Partida: Um teatro político na ditadura militar Entrevista com Antonio Petrin concedida à Marco Antonio Pedra da Silva

Figura 2 - Antonio Petrin

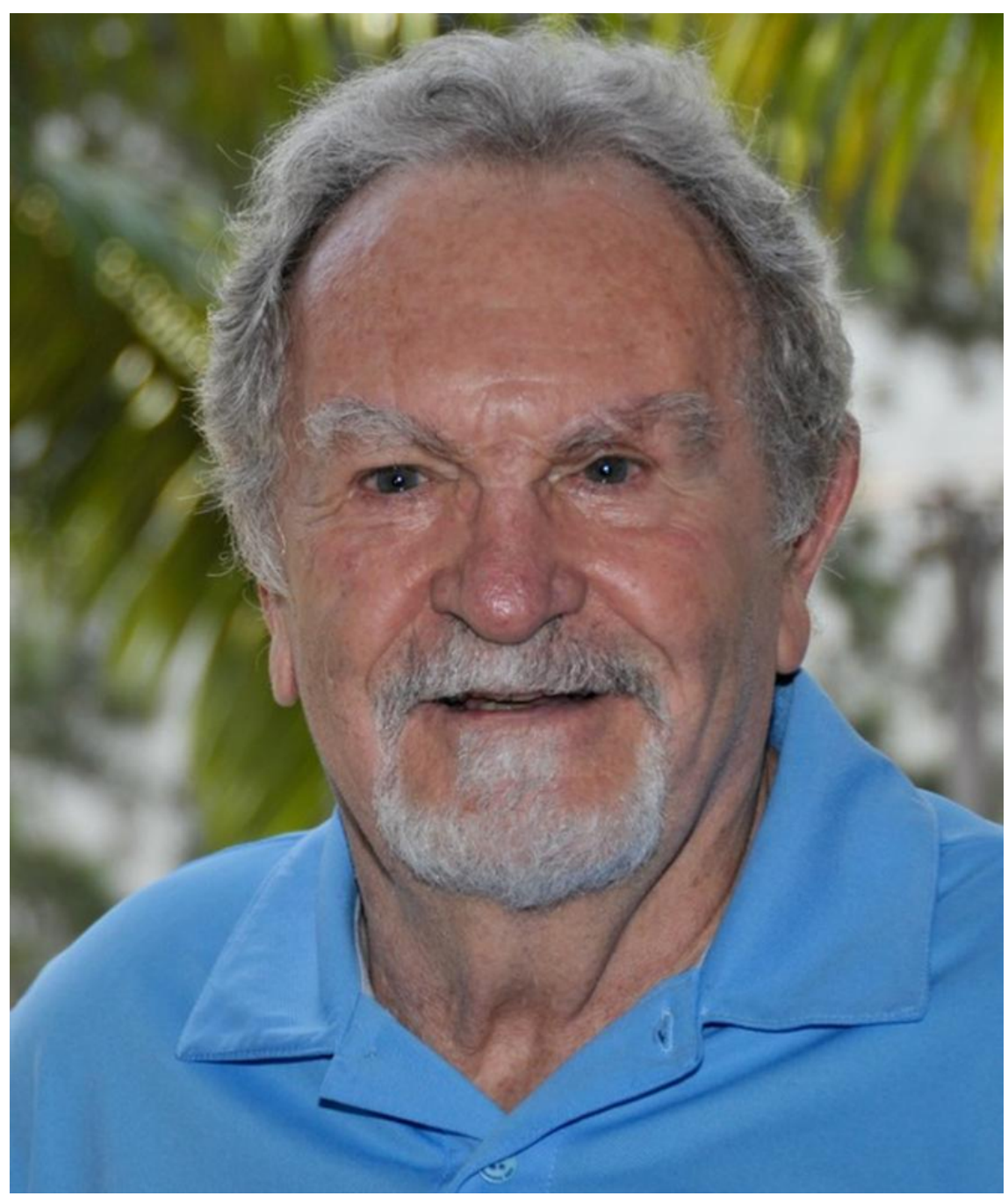

Fonte: https://mubi.com/pt/cast/antonio-petrin

Recebido em: 21/06/2021

Aprovado em: 30/09/2021

Universidade do Estado de Santa Catarina - UDESC

Programa de Pós-Graduação em Teatro - PPGT

Centro de Arte - CEART

Urdimento - Revista de Estudos em Artes Cênicas

Urdimento.ceart@udesc.br 